da Comunidade no desenvolvimento e no grau de justiça alcançado com o diretito comunitário Nessler, págs. 206 e seguintes.

57 Note-se que a modificação das normas constitucioomplexo, pois enquanto várias delas (arts. 171, 172,
$73,176,177,179$, por exemplo) discriminam o capital estrangeiro, estabelecendo privilégios e monopólios as pessoas jurídicas nacionais de capital nacional ou pesas jurídicas de direito público, o governo brasileiro O-Brasileiras, tentando atingir um tratamento igualitário.

\title{
As contribuições especiais na Constituição de 1988
}

\section{Rômulo Maya}

Professor da UFRGS

Vice-Presidente do Tribunal Administrativo de

Recursos Fiscais do Rio Grande do Sul

As contribuições especiais são antigas no Brasil. Desde 1923, a Lei Eloy Chaves, criando a Caixa de Aposentadoria e Pensões dos Ferroviários, as instituiu. No mesmo ano, por força da Lei $n^{\circ}$ 5.109, aquele regime previdenciário foi estendido aos marítimos. A partir de 1934, com a criação da previdência social das demais categorias profissionais, através dos IAPs (Bancários, Comerciários, Industriários, etc), elas começam a proliferar. Em 1943, a CLT estabeleceu, nos arts. 578 e seguintes, o "imposto sindical", mais tarde acertadamente transformado pelo art. 217 do CTN em contribuição sindical. Daí em diante, principalmente a partir da década de 60, avolumaram-se as contribuiçōes especiais, também chamadas de parafiscais, em nosso país, estendendo-se a outros setores de atividade, tais como, por exemplo, o de intervenção da União no domínio econômico.

2. - Apesar da intensidade do fenômeno e de sua grande repercussão na própria vida nacional, as contribuições especiais não tinham sido objeto de ordenamento individualizado por parte de nossos constituintes. As Constituições de 34, 37, 46 e 67 delas não cogitaram expressamente, não obstante a elas se referissem quando versaram a previdência social. Só a Emenda nº 1, de 1969 , preocupou-se em outorgar às contribuições parafiscais a condição de figura constitucional.

3. - Como é sabido, a Lei Maior de 69 , em sua redação original, no art. $21-\S 2^{\circ}$ I, atribuiu à União a exclusividade para instituir contribuições, nos seguintes ter mos:

"21- $§ 2^{2}-$ A União pode instituir:
I - contribuições, nos termos do item I deste artigo, tendo em vista intervenção no domínio econômico e o interesse da previdência social ou de categorias profissionais."

4. - Algumas considerações podem ser tecidas sobre este texto. Em primeiro lugar. não se permitiu aos Estados e Municípios a instituição de contribuições, tolerando-se apenas as que decorressem do estabelecimento do regime previdenciário dos funcionários estaduais e municipais, como é o caso, por exemplo, da contribuição em favor do Instituto de Previdência do Estado do Rio Grande do Sul.

5. - Em segundo lugar, a doutrina tributária entendeu que, do dispositivo acima transcrito, poder-se-iam deduzir três espécies de contribuições especiais ou parafiscais, a saber, as decorrentes da intervenção da União no domínio econômico, tais como a em favor do I.A.A. e demais institutos federais congêneres, as no interesse da previdência social, como, por exemplo, a em favor do INSS, e as de interesse de categorias profissionais, como a contribuição sindical e a instituída pela $O A B$.

6. - Por 'outro lado, a inclusão dessas contribuições no capítulo relativo ao Sistema Tributário Nacional acentuou, confor me expressiva maioria dos autores e até mesmo de várias decisões de nossos tribunais, a sua natureza tributária. Além disso, com referência às contribuições, aplicava-se a faculdade prevista no item I do art. 21, relativa à importação de produtos estrangeiros, isto é, possibilitava-se ao Poder Executivo, nas condições e nos limites estabelecidos 
em lei, alterar as suas alíquotas ou as suas bases de cálculo.

7. - Admitida a natureza tributária das contribuições especiais, certos efeitos de suma importância produziram-se. Entre eles a fixação dos prazos de decadência e de prescrição, para seu lançamento e cobrança judicial, em cinco anos, a teor do disposto nos arts. 173 e 174 , respectivamente, do C.T.N., em decorrência de jurisprudência predominante, com forte apoio na doutrin nacional Outras conseqüências seriam sua submissio aos princípios constitucionais tributários e às normas gerais de direito tributário.

8. - Essa orientação feriu os interesses da Previdência Social federal, que passou a lutar pelo reconhecimento pleno do disposto no art. 144 da Lei no 3.807/60 (Lei Orgânic da Previdência Social), que outorga o prazo de 30 anos para a cobrança de suas contribuições. Estes e outros fatores fizeram com que pelo denominado "Pacote de Abril" Emenda Constitucional no ${ }^{\circ}$, de abril de 1977 - fosse alterada a redação do art. 21 $\S 2^{\circ}$ - I, da Lei Maior de 1969, para o seguinte teor

"Art. $21-\S 2^{\circ}$ - a União pode instituir:

I - contribuições, observada a faculdade prevista no item I deste artigo, tendo em vista a intervenção no domínio econômico ou o interesse de categorias profissionais e para atender diretamente à parte da União no custeio dos encargos da previdência social."

9.- Desse modo, as espécies de contribuições parafiscais previstas expressamente naquele texto constitucional passaram a ser:

a) decorrentes da intervenção da União no domínio econômico

b) no interesse de categorias profissionais

c) destinadas a atender diretamente a parte da União nos encargos da previdência social, tais como as conhecidas "quotas de previdência", a que aludem, por exemplo, os arts. 71 e 74 da Lei no $3.807 / 60$ (LOPS) com as alterações determinadas pelo art. 34 da Lei $n^{\circ}$ 4.863/65.
10. - Como se vê, houve uma substituição da espécie "contribuições no interesse da previdência social" pela espécie "contribuições destinadas a atender diretamente à parte da União no custeio dos encargos da previdência social", em relação ao texto original de 1969. As outras duas espécies permaneceram as mesmas.

11. - Pela referida Emenda, as contribuições previdenciárias propriamente ditas foram transferidas para o art. 43 da C.F., que tratava das atribuições do Congresso Nacional, acrescentando-se a ele um novo item, o "X", incluindo as "contribuições sociais", denominação dada às contribuições previdenciárias, entre elas as previstas nos arts. § 4, e 178. Pretendeu-se com a transposição de local, descaracterizar a natureza tributária das contribuições sociais, o que em parte foi conseguido, pois o Supremo Triparte foi con am decisões inicialmente relatadas pelo Min. Moreira Alves, entendeu que as referidas contribuições deixaram de ser tributos a partir da Emenda $\mathrm{n}^{\circ} 8$.

12. - Tal orientação não foi aceita pacificamente pela doutrina tributária brasileira que, em grande parte, continuou sustentando que as contribuições sociais permaneciam com natureza tributária. Não seria um simples deslocamento no texto constitucional que iria modificar sua substância. Como disse conhecido tributarista nacional, não seria a localização topográfica no texto constitucional que iria alterar-lhes a natureza jurídica.

13. - Não havia amainado a discussão sobre o tema, quando sobreveio a atual Constituição, promulgada em 05 de outubro de 1988. Nela, em seu artigo 149, contemplam-se as contribuições especiais ou parafiscais na maneira seguinte:

"Art. 149 - Compete exclusivamente à União instituir contribuições sociais, de in tervenção no domínio econômico e de interesse de categorias profissionais ou econômicas, como instrumento de sua atuação nas respectivas áreas, observado o disposto nos arts. 146 - III, e 150 - I e III, e sem prejuízo do previsto no art. $195-\S 60$ relativamente às contribuiçōes a que alude o dispositivo.

Parágrafo único - Os Estados, o Distrito Federal e os Municípios poderão instituir contribuição cobrada de seus servidores, para custeio, em benefício destes, de sistemas de previdência e assistência social."

14. - De plano verifica-se que algumas modificações de vulto foram feitas pelo texto novo. Eliminou-se a faculdade de alterar as alíquotas e a base de cálculo pelo Executivo, dentro de limites fixados em lei. Manteve-se a exclusividade da União para instituir as contribuições, mas legitimaram-se expressamente as contribuições estaduais ou municipais para custeio de sistemas de previdência em favor de seus funcionários, abrindo assim uma exceção à regra.

15. - Além disso, consagrada ficou a denominação de "contribuições sociais", mas com um espectro bem mais amplo que as previstas no art. 43, X, da Constituição anterior. E, por fim, pela expressão "como instrumento de sua atuação nas respectivas áreas", estabeleceu-se um fundamento ou uma causa para a instituição das contribuições, cuja inobservância pode levar à alegação de inconstitucionalidade da exação. Não se poderá criar uma contribuição sem que haja uma atuação concreta da União na respectiva área. Também importante é a necessidade da observação dos arts. 146, III, 150 , I e III, e dos demais princípios comuns a todos os tributos, decorrente de sua natureza tributária.

16. - O exame conjunto dos arts. 149 e 195 da atual Carta Magna permite que se classifique as contribuições especiais, igualmente, em três espécies:

I) contribuições sociais

II) contribuições de intervenção no domínio econômico

III) contribuições de interesse de categorias profissionais ou econômicas

As espécies II e III identificam-se, praticamente, com as suas antecessoras do art. 21, § 2º I, da Emenda no 1 , de 1969, com o pequeno acréscimo da locução "ou econô micas" no tipo III. Os exemplos dados anteriormente servem para elas agora também.
17. - Por sua vez as contribuições sociais se subdividem em duas espécies:

a) contribuições sociais de seguridade social (art. 195, I, II e III);

b) contribuições sociais sem essa finalidade específica (art. 149).

As contribuições sociais de seguridade social visam a assegurar, na ordem social, os direitos relacionados com a saúde, a previdência social e a assistência social, tratados nos arts. 196 a 204 da Lei Suprema vigente. São seus exemplos as contribuições previdenciárias em geral. As outras contribuições sociais são destinadas a satisfazer outros direitos sociais, como os relativos à educação, ao trabalho, à segurança, etc. Entre elas, verbi gratia, o salário-educação.

18. - A classificação em contribuições sociais de seguridade social e contribuiçōes sociais simples é importante porque às primeiras não se aplica o princípio da anterioridade, expresso no art. 150, III-b, da C.F., podendo ser exigidas desde que decorrido noventa dias da publicação da lei que as houver criado ou aumentado, a teor do disposto no art. $195, \S 6^{\circ}$, da mesma Constituição. As contribuições sociais simples, ao reverso, estão sujeitas ao dito princípio, nos termos do art. 149 , não podendo ser cobradas no mesmo exercício financeiro em que tenha sido publicada a lei que as instituiu ou aumentou.

19. - Uma observação especial merecem as contribuições de interesse de categorias profissionais, mais especificamente as exigi das pelos órgãos de fiscalização do exercicio de profissões liberais, tais como as cobradas pelos Conselhos de Medicina, Engenharia, Economia e a Ordem dos Advogados do Brasil.

20. - Como vimos, no art. 149 da Constituição, as contribuições especiais, entre as quais se encontram as de interesse de categorias profissionais ou econômicas, estão sujeitas ao disposto nos arts. 146, III, e 150 I e III, da C.F. Isto significa que tais contribuições necessitam estar definidas em lei complementar, não podem ser exigidas ou aumentadas sem lei que as estabeleça, nem incidir sobre fatos geradores ocorridos an- 
tes do início da vigência da lei que as houver instituído ou aumentado, ou serem cobradas no mesmo exercício financeiro em que haja sido publicada a lei que as instituiu ou aumentou.

21. - Ora, a exigência dessas contribuições pelos ditos Conselhos Profissionais está regulada pela Lei $n^{\circ} 6.994$, de 26.5 .82 que fixou os seus valores e modo de cobrança e inclusive sua atualização. Em relação à Ordem dos Advogados, porém, a exigênci da contribuição aos nela inscritos está disciplinada nos arts. 140 e 141 dos seus Estatutos - Lei $\mathrm{n}^{\circ}$ 4.215, de 27.4.63. Deixou, porém, o dito art. 141 ao inteiro arbítrio das Seccionais a fixação dos valores das contribuições, as quais são aumentadas anualmente sem nenhuma lei que prevej ou estabeleça tais aumentos.

22. - Parece, assim, com a vigência da atual Constituição, que as contribuições cobradas pelas Seções Estaduais da OAB, por desobedecerem o disposto no art. 150, I e III-b, são inconstitucionais. Sabe-se, por outro lado, que a Ordem está pretendendo elaborar novos estatutos, existindo já um anteprojeto publicado para que se façam sugestōes. Seria, pois, conveniente que neles se sanasse a irregularidade em causa.

23. - Uma referência à denominada "contribuição sindical", prevista no art. 580 da CLT, que atinge também os profissionais liberais, com exceção dos advogados (Lei no
$4.215 / 63$, art. 142), parece-nos pertinente. Foi a mesma fixada de maneira tal que su atualização se faz automaticamente, sem necessidade de lei nova.

24. - Por derradeiro, uma observação sobre a natureza jurídica das contribuições especiais ou parafiscais. Cremos que os constituintes de 1988 perderam uma ótima oportunidade para estabelecer definitivamente a natureza tributária dessas exações. Bastaria que as incluíssem no art. 145 juntamente com os impostos, taxas, contribuição de melhoria e também os empréstimos compulsórios.

25. - Em todo o caso, com o retorno das contribuições sociais ao capítulo do sistema tributário, pode-se supor que se voltará a entender terem elas natureza tributária, contrario sensu do que foi entendido quando de sua passagem para o item $X$ do art. 43 da Emenda Constitucional nº 1, de 1969. 26. - A propósito, cite-se a opinião de Ives Gandra da Silva Martins, em seu conhecido "Sistema Tributário na Constituição de 1988", no qual afirma, à pág. 114, expressamente, que encerrou-se definitivamente a polêmica sobre a natureza jurídica das contribuições especiais, tida por ele como tributária face às disposições da Carta Magna vigente. Sustenta mais o referido autor que a instituição das contribuições, se tributos, só poderá ocorrer nos termos do art. 146, III, da Constituição Federal.

\section{Conceito e fundamentos de família e sua evolução na ordem jurídica}

Carlos Silveira Noronha

Professor de Teoria Geral do Processo, de Direito Processual Civil e de

Direito Civil na Faculdade de Direito da UFRGS

Sumário: 1 . Origem natural e sociojurídica da família; 2. A linha romana de constituição da família; 3. A família perante o direito divino e o direito canônico; 4. A família no direito moderno; 5 . Natureza jurídica da família; 6. A família no direito pátrio; 7. Entes afins à família; 7.1 Concubinato; 7.2 Entidade familiar; 8 . Família substituta.

\section{Origem natural e sociojurídica da} família

Têm sido objeto da mais ampla especulação em todos os tempos e em todas as organizações sociojurídicas, os modos pelos quais surgiu e se constituiu a família. A origem natural, embasada simplesmente na satisfação da concupiscência resultante da diversidade de sexos e no fato biológico da procriação necessária à conservação da espécie, restaria por estabelecer paridade ou indistinção entre os comportamentos do ho mem e dos animais. Pouco provável se apresenta tal origem familiar, especialment à luz da concepção clássica do direito natural, segundo a qual os fins pessoais do homem e a sua própria felicidade só podem ser alcançadas com o auxílio dos seus semelhantes, em sociedade, respeitando os direitos dos outros e satisfazendo as exigências da vida em comum.

A família, desse modo constituída, atenderia apenas à satisfação pura e simples de apetites inferiores e egoísticos do homem da mulher, e não se conformaria com a razão humana, nos limites do aequum et bonum, da sentença de Paulo (D. 1.1.11), em que originariamente se funda a lei natural ${ }^{1}$.

Naquele distante e primitivo estágio de convivência humana, ignorados ou desprezados eram os vínculos matrimonais e $d$ consangüinidade dos consortes entre si destes com sua prole, que hoje constituem o núcleo familiar, fruto da evolução socio- cultural e que passou a chamar-se família natural ou família biológica, ainda que ausentes estejam os vínculos civis do casamento. Nem o darwinismo com a sua teoria transformista, afirmando que a espécie humana descende de espécies animais, seria capaz de dar suporte a essa primeva situação como forma originária da família ${ }^{2}$.

Especulam outros autores que a família primitiva teria origem na poligamia ou na poliandria ${ }^{3}$, ou, ainda, na promiscuidade de sexos $^{4}$, ou seja, no grupo formado por um homem e algumas mulheres e os respectivos filhos, ou na união de uma mulher com alguns homens e a sua prole, ou ainda, teria origem numa promiscuidade de sexos, esta sustentada por exíguo período temporal ${ }^{5}$. A primeira ensejaria a forma do patriarcado; a segunda, o matriarcado; e na terceira se consubstanciaria a união livre de sexos, sem vínculos civis e sociais ${ }^{6}$.

Dentre a vasta gama de teorias que investigam o problema da origem da família, a que se ampara em fundamentos mais aceitáveis é a de que a origem desta célula social está no patriarcado, que inicialmente teria se manifestado sob a forma poligâmica, transformando-se em monogâmica com a evolução social, tendo-se em vista que a molécula fundamental das sociedades antigas era a família sujeita ao pai.

Naqueles tempos, a julgar pelos hábitos sociais do homem moderno e da poligamia de quase todos os selvagens, não se deve pôr 